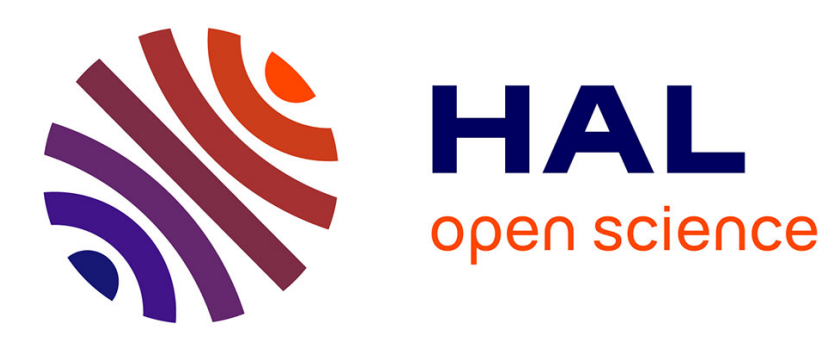

\title{
A first damage modelling of SiC-SiC laminates under dynamic loading
}

O. Allix, F. Bras, J.-F. Deü

\section{To cite this version:}

O. Allix, F. Bras, J.-F. Deü. A first damage modelling of SiC-SiC laminates under dynamic loading. Journal de Physique IV Proceedings, 1994, 04 (C8), pp.C8-527-C8-531. 10.1051/jp4:1994882 . jpa00253443

\section{HAL Id: jpa-00253443 https://hal.science/jpa-00253443}

Submitted on 1 Jan 1994

HAL is a multi-disciplinary open access archive for the deposit and dissemination of scientific research documents, whether they are published or not. The documents may come from teaching and research institutions in France or abroad, or from public or private research centers.
L'archive ouverte pluridisciplinaire HAL, est destinée au dépôt et à la diffusion de documents scientifiques de niveau recherche, publiés ou non, émanant des établissements d'enseignement et de recherche français ou étrangers, des laboratoires publics ou privés. 


\title{
A first damage modelling of SiC-SiC laminates under dynamic loading
}

\author{
O. Allix, F. Bras* and J.-F. Deï*
}

IUT/GMP, Université d'Evry, Laboratoire de Mécanique et Technologie, ENS de Cachan, CNRS, Université Paris VI, 6I Avenue du Président Wilson, 94235 Cachan cedex, France

* Département Matériaux en Conditions Sévères, Centre de Recherches et d'Etudes d'Arcueil, ETCA, I6 bis Avenue Prieur de la Côte d'Or, 94114 Arcueil cedex, France

\begin{abstract}
Résumé : Un premier mésomodèle permettant de simuler le comportement mécanique d'un pli élémentaire au sein d'un composite $\mathrm{SiC}-\mathrm{SiC}$ stratifié sous chargement dynamique est proposé. Le problème de son identification et de son utilisation pour la prévision de la rupture dynamique de structures stratifiées $\mathrm{SiC}-\mathrm{SiC}$ est discuté.
\end{abstract}

\begin{abstract}
A first mesomodelling, which allows us to describe the mechanical behaviour of an elementary ply within a SiC-SiC laminate under dynamic loading, is proposed. Questions related to its identification and its use for the prediction of the dynamic fracture of laminated structures are discussed.
\end{abstract}

\section{Introduction}

The aim of this study is the analysis of SiC-SiClaminate mechanical behaviour under dynamic loading. In fact, new aircraft ballistic protections, which are light and may be used at rather high temperatures $\left(400^{\circ} \mathrm{C}\right.$ ), are currently under study. For these applications, a two layer concept is developed with a ceramic in front of the $\mathrm{SiC}-\mathrm{SiC}$ ceramic-ceramic composite. It is thus important to precisely know the mechanical behaviour rate dependence of the different components in order to calculate the protection. Here, the interest is focused on the $\mathrm{SiC}-\mathrm{SiC}$ laminate.

The mesomodelling concept has been previously defined in (1) and applied to laminates in (2). For the studied material two elementary mesoconstituents are defined: the elementary ply and the interlaminar interface. For the fracture prediction the damage state of each elementary ply is assumed to be constant throughout the thickness. The interlaminar interface is introduced for delamination analysis (2) and will not be studied in this paper which is devoted to the elementary ply modelling.

The static mechanical behaviour is mainly an elastic and damageable one. Moreover rate dependence behaviour occurs for high rate loadings or very close to fracture. To model these rate effect delay damage modelling is introduced. In dynamic situation such a modelling avoids numerical difficulties such as mesh dependency.

In order to identily the elementary ply modelling both static and dynamic tests have been performed. When using a split Hopkinson bar $(3,4)$ for dynamic tests, due to a very low level of strain at rupture, difficul- 
ties have been encountered. In fact this was not the case for metallic materials also studied on the experimental device of E.T.C.A. (5).

\section{Modelling of the elementary ply behaviour under static loading}

The elementary ply behaviour under static loading appears to be an elastic and damageable one. To model the damage (i.e. the gradual development of microcracks) an idea, issued from L.M.KACHANOV (6), is to use the variation of Young's modulus as an indicator of damage. This principle, i.e. the classical theory of isotropic damage, is not sufficient to describe the ply behaviour, which is anisotropic and presents an unilateral feature. A theory proposed by P.LADEVEZE (1) which takes these properties into account is used here.

A plane-stress state is assumed, and thus only the plane part of strains is taken into account. In what follows, subscripts 1 and 2 respectively designate the fibre and the transverse direction.

In such a situation the damage material strain energy density appears to have the following expression:

$$
E_{d}=\frac{1}{2}\left[\frac{\left\langle\sigma_{11}\right\rangle_{+}^{2}}{E_{1}^{0}\left(1-d_{1}\right)}+\frac{\left\langle\sigma_{11}\right\rangle_{-}^{2}}{E_{1}^{0}}+\frac{\left\langle\sigma_{22}\right\rangle_{-}^{2}}{E_{2}^{0}}+\frac{\left\langle\sigma_{22}\right\rangle_{+}^{2}}{E_{2}^{0}\left(1-d_{2}\right)}+\frac{\sigma_{12}^{2}}{G_{12}^{0}\left(1-d_{12}\right)}-\frac{2 v_{12}^{0}}{E_{1}^{0}} \sigma_{11} \sigma_{22}\right]
$$

with

$$
<a\rangle_{+}=\frac{a+|a|}{2} \text { and }<a>_{-}=\frac{a-|a|}{2},
$$

$d_{1}, d_{2}, d_{12}$ are scalar-damage variables which are uniform throughout the ply thickness (2). If the microcraks are loaded in compression, they close up and then have no effect on the behaviour. This explains the separation of the energy into two parts : one "tensile" part and one "compressive" part. Damage energy release rates $\mathrm{Y}_{1}, \mathrm{Y}_{2}, \mathrm{Y}_{12}$ associated with variables $\mathrm{d}_{1}, \mathrm{~d}_{2}, \mathrm{~d}_{12}$ are introduced:

$Y_{1}=\left(\frac{\partial E_{d}}{\partial d_{1}}\right) \sigma=\frac{\left[\left\langle\sigma_{11}\right\rangle_{+}^{2}\right]_{m}}{2 E_{1}^{0}\left(1-d_{1}\right)^{2}} ; Y_{2}=\left(\frac{\partial E_{d}}{\partial d_{2}}\right) \sigma=\frac{\left[\left\langle\sigma_{22}\right\rangle_{+}^{2}\right]_{m}}{2 E_{2}^{0}\left(1-d_{2}\right)^{2}} ; Y_{12}=\left(\frac{\partial E_{d}}{\partial d_{12}}\right) \sigma=\frac{\left[\sigma_{12}^{2}\right]_{m}}{2 G_{12}^{0}\left(1-d_{12}\right)^{2}}$

where []$_{m}$ indicates the average value trough the thickness of one ply. These damage release rates are assumed to govern the damage evolution. In a first instance, simple damage evolution laws are used :

$$
\mathrm{d}_{\mathrm{i}}(\mathrm{t})=\mathrm{f}_{\mathrm{i}}\left(\underline{Y_{\mathrm{i}}}\right) \text { with } \underline{Y_{\mathrm{i}}}=\operatorname{Sup}_{\zeta \leq \mathrm{t}}\left(\mathrm{Y}_{\mathrm{i}}(\zeta)\right)
$$

\section{Identification of the static behaviour}

Tests are performed on cross ply laminates. The classical laminate theory is then used to obtain information at the scale of the elementary ply. Tension tests, with unloadings in order to measure apparent damages, have been performed on $[0]_{s},[0,90]_{s}, \cdot[+45,-45]_{s}$ laminates. This gives the damage characteristic functions $f_{i}$. For instance, the "shear" behaviour is identified by a $[+45,-45]_{s}$ tension test. The relations between the test values and the ply values are : $\sigma_{12}=\sigma^{*} / 2, \varepsilon_{12}=\left(\varepsilon^{*}-\varepsilon_{t}^{*}\right) / 2$ where $\sigma^{*}$ is the longitudinal applied stress, $\varepsilon^{*}$ and $\varepsilon^{*}$ are the longitudinal and transverse strains measured by strain gauges. The function $\mathrm{f}_{12}$ may be approximated by two straight lines (figure 1 ). This is sufficient to properly simulate the "shear" response of the elementary ply (figure 2). 


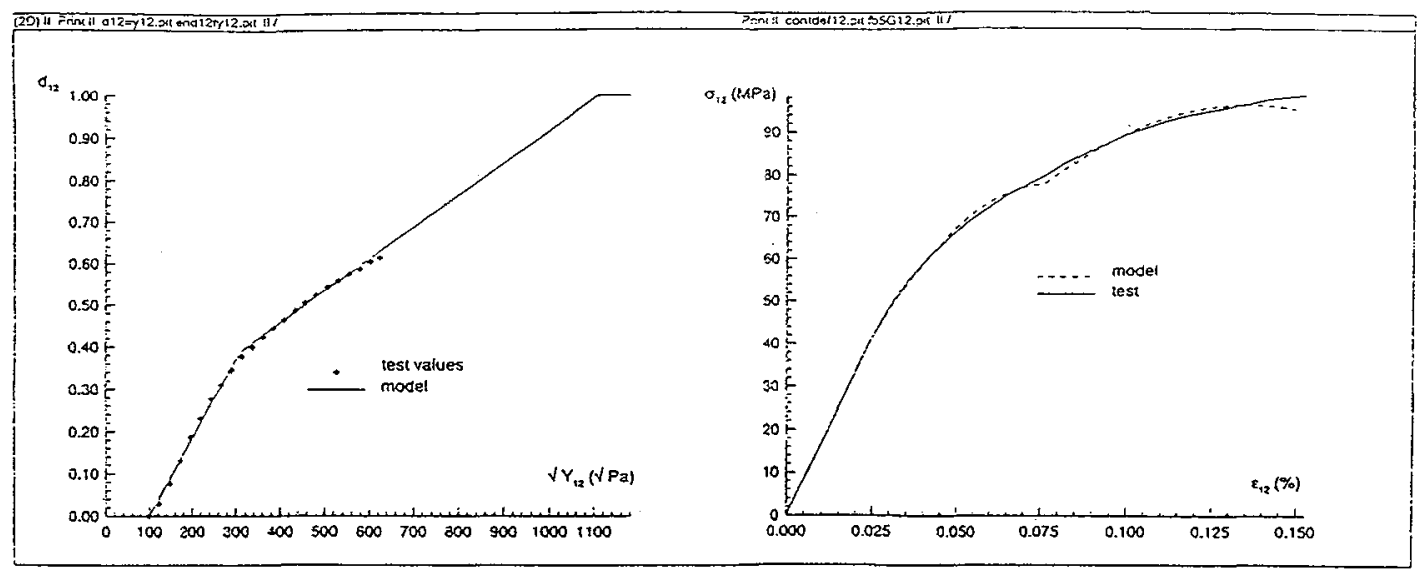

Figure $1: d_{12}=f_{12}\left(Y_{12}\right)$

Figure 2: $\sigma_{12}$ versus $\varepsilon_{12}$

\section{Rate effects}

It is now a well known property that classical damage theories lead to a spurious mesh dependency, related in dynamics to the loss of hyperbolicity. A way to avoid such numerical behaviour is to use localization limiters (7). A large class of these limiters has been studied by De BORST and SLUYS (8). In this study we have chosen to use a meso-modelling combined with a delay damage modelling (1) in order to respect the properties that : - the model is in agreement with the static experiments,

- the size of the fracture process zone is in order of magnitude of the thickness of the ply.

The second consideration leads to clearly distinguish these delay damage modellings from classical visco-elastic or visco-anelastic modellings. To ensure the first property the following expression is introduced:

$\dot{d}_{\mathrm{i}}=k\left(f_{i}\left(Y_{i}\right)-d_{i}\right\rangle_{+}^{n} \quad$ where $f_{i}$ is the characteristic damage function identified by a static test.

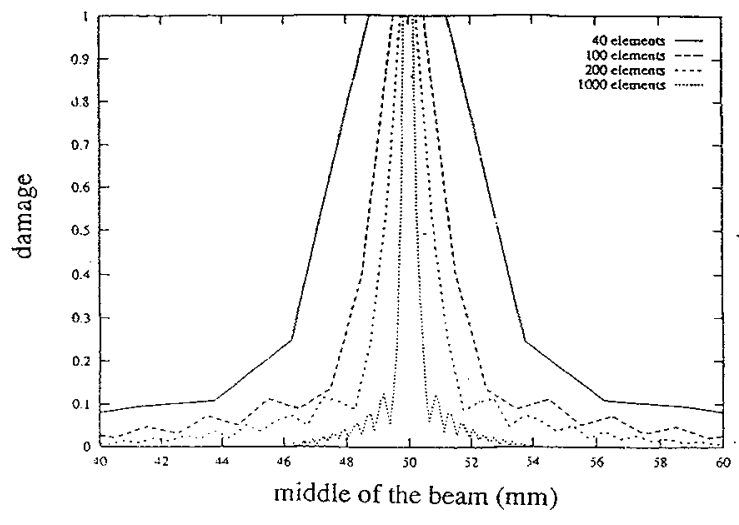

Figure 3 (a) : damage modelling

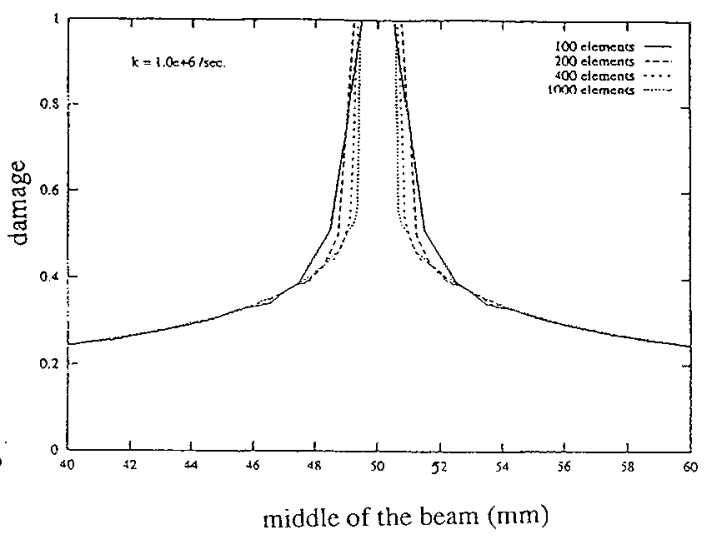

Figure 3 (b) : delay damage modelling

Let us consider the classical example of a bar submitted to two tension pulses which, by combining in the middle of the bar, lead to the fracture of the specimen. The bar is divided into Finite Element (F.E.) of the satme size and a central difference scheme with a lumped mass matrix is used (9). On figure 3 (a) it is shown that for the model presented in section 2, the size of the fracture area is the same as the size of the F. E. which 
is used. On the contrary (figure 3 (b)), for the delay damage modelling, the size of the fracture area is independent of the size of the F. E. for element size lower than $2 \mathrm{~mm}$, which is the size of the fracture area obtained in this example with a value of $1 / \mathrm{k}$ of $1.010^{-6} \mathrm{~s}(\mathrm{n}=1.0)$.

Moreover, for this example, the ratio $1 * k / C_{e} \approx 0.22$ where 1 is the size of the fracture area and $C_{e}$ is the elastic speed (for values of $\mathrm{k}$ comprised between $1.010^{+6}$ and $5.010^{+6} \mathrm{~s}^{-1}$ ) is obtained. This could allow to identify $\mathrm{k}$ by measurement of the experimental size of the fracture process zone.

\section{First identification of the delay damage modelling}

The identification of the delay damage modelling requires high rate loadings. One of the simplest dynamic testing device is the split Hopkinson compressive bar $(3,4)$. Considering that there is no damage in compression neither in the fiber direction nor in the transverse one, a $[+45,-45]_{\mathrm{S}}$ is used in order to test the practibility of the proposed method. A first difficulty is the very low level of strains at fracture $(0.2 \%$ on static tension test on $[+45,-45]_{s}$ ) which leads to leave the hypothesis of an equilibrium state of the specimen often used for the identification. Thus a numerical tool has been developed which is based on:

- a one dimensional wave propagation assumption,

- a description of the laminate throughout the thickness,

- a central difference scheme with a lumped mass matrix (9).

In order to make the computation of the specimen only, information obtained by measures of strain gauges placed on the incident and transmitted bars are transfered to the edges of the specimen by means of the elastic celerity of the bars. Strain gauges are placed on the upper and lower faces of the specimen. A strong parasitic bending effect has been observed. This was not the case for tests on metallic materials. This difference could be explained by the important difference between the maximum strain levels of these two kinds of materials. Thus the device testing has been improved and more reliable tests are now being performed with a parasitic bending leading to a difference of $20 \%$ in the level of strain between the two faces.

Experimentally the specimen fracture occurs for test values of the longitudinal strain $\varepsilon_{\mathrm{x}}$ nearly equal to $0.15 \%$ (figure 4 ).

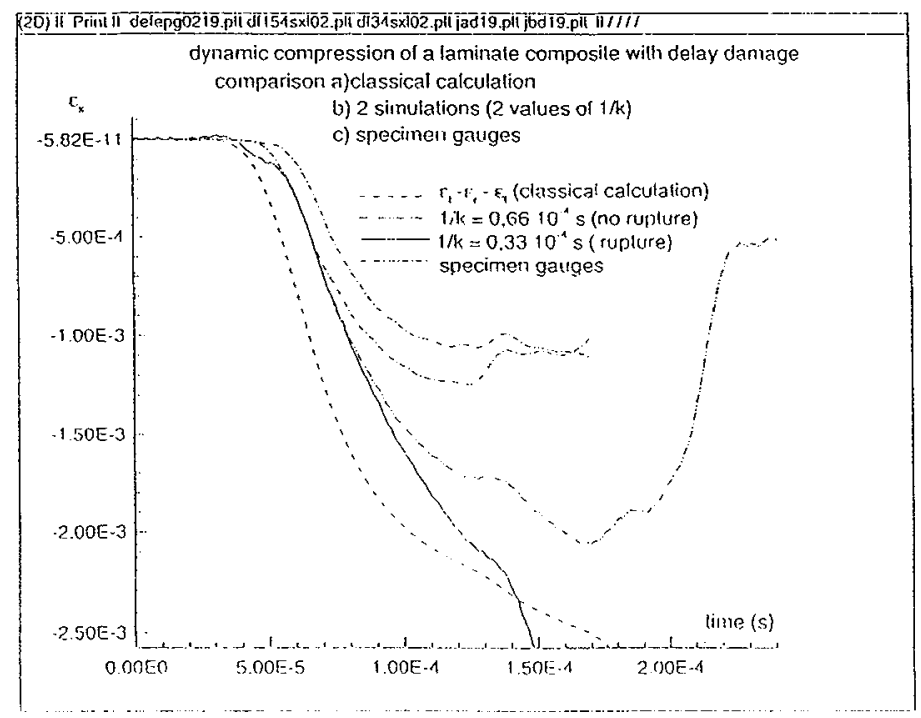

Figure 4 : First comparison simulation - experiment

In fact the fracture has been obtained for five out of six tests performed. By simulation with $1 / k=1.0$ $10^{*} \mathrm{~s}(\mathrm{n}=1.0)$ no numcrical rupture was obtained, which was not the case for $1 / \mathrm{k}=0.3310^{-4} \mathrm{~s}$. These exper- 
imental and numerical results lead to two main remarks. The first is that, assuming that the simulation of the test is correct (one dimension hypothesis in particular), a rate effect is obtained because with no delay $(\mathrm{k} \rightarrow \infty)$ the fracture of the specimen would be obtained in everyone of the previous cases. The second remark is that it is possible to adapt the value of $k$ in order to get this rate effect. Due to experimental difficulties, which does not permit us to precisely compare the values of experimental and numerical local strains, we are not able, at present, to know whether this rate effect is correct.

More precisely, for a value of time greater than $1.010^{-4} \mathrm{~s}$ the computation shows that the strain is nearly uniform on the specimen. In that case the classical calculation of strains using the experimental velocities of the incident and transmitted bars (10) should give the same values than the gauges on the specimen (even if some parasitic effects are present). This is not the case but the computed values of strains are comprised between the experimental results given by the strain gauges and the one given by the classical calculation (10). Furthermore it is shown on figure 4 that for $1 / \mathrm{k}=0.6610^{-4} \mathrm{~s}$ no numerical rupture is obtained, which is not the case for $1 / \mathrm{k}=0.3310^{-4} \mathrm{~s}$.

Another experimental result is that the ultimate fracture mechanism is delamination. Thus the dynamical identification of the elementary ply behaviour performed here is valid only if delamination results of a fracture of the elementary ply itself, which is assumed here. A more precise study related to this problem is in progress.

\section{Conclusion}

To describe the dynamical behaviour of $\mathrm{SiC}-\mathrm{SiC}$ laminates one proposes to use a delay damage modelling. Two kind of results have been obtained and presented in this paper. The first result is that, using a delay damage modelling, no spurious mesh dependency is obtained. The second one is that this first study of this type of model in dynamics shows its capability to describe the experimental rate effects obtained on tests, at least for the prediction of the fracture.

\section{References}

\section{(1) P.LADEVEZE}

"A damage approach for composite structure: theory and identification" Mechanical Identification of Composites, Elsevier Applied Science, p 44-57, 1990.

(2) P.LADEVEZE, O.ALLIX, L.DAUDEVILLE

"Mesomodeling of damage for laminate composites. Application to delamination"

Inelastic Deformation of Composites Materials, Springer-Verlag, Dvorak ed., p. 607-622, 1990.

\section{(3) D.HOPKINSON}

Phil. Trans. Roy. Soc., A 213, p. 437, 1914.

\section{(4) H.KOLSKY}

"An investigation of the mechanical properties of materials at very high rates of loading" Proc. Phys. Soc., B 62, p. 676, 1949.

\section{(5) S.GABELOTAUD, C.NGUY}

"Compression dynamique du titane : resultats experimentaux et modelisation"

Rapport E.T.C.A. 91 R 20

\section{(6) L.M.KACHANOV}

"Time of the rupture process under creep conditions"

Izv Akid Nauk SSR Otd Tekh Nauk N08, 1958, p. 26-31. 